\title{
Transformational Leadership, Knowledge Sharing and Innovation Capability: An Empirical Study from Lao Firms
}

\author{
Leaungkhamma Lathong $^{1}$ \\ Le Ba Phong ${ }^{2 *}$ \\ Pitcha Saeheng ${ }^{3}$ \\ School of Business Administration, Hunan University, Changsha, China ${ }^{1,3}$ \\ Hanoi University of Industry, Bactuliem, Hanoi, Vietnam ${ }^{2 *}$
}

\begin{abstract}
The purpose of this paper is to examine the effects of transformational leadership and knowledge sharing on innovation capability in term of individual and organizational innovation capability. This study used Structural equation modelling (SEM) to check proposal hypotheses using empirical data collected from 216 participants at 45 small and medium enterprises in Laos. The research findings revealed that knowledge sharing mediates the relationship between transformational leadership and innovation capabilities. Notably, the findings highlight the greater influence of TL on organizational innovation capability in comparison with its effect on individual innovation capability. In contrasts, knowledge sharing activities induce greater influence on individual innovation capability compared with its effect on organizational innovation capability. The paper has, therefore, significantly advanced our insights of how transformational leaders foster employee knowledge sharing activities for stimulating innovation capabilities of organizations.
\end{abstract}

Keywords: Transformational Leadership; Knowledge Sharing; Individual Innovation Capability; Organizational Innovation Capability

\section{*Corresponding author: Le Ba Phong; Email: lebaphong.vn@gmail.com DOI: https://doi.org/10.37227/jibm-2021-08-1154}

\begin{abstract}
Introduction
Innovation capability is widely perceived as a critical factor for the survival, growth and competitive advantage of organizations (Le \& Lei, 2019; Le, 2020; Gui et al., 2021). Scholars recognized that innovation capability of firms allows them to adapt effectively with the lack of certainty of both external and internal environment, and bring firms the success in the dynamic markets in long term (Le \& Lei, 2018; Yang et al., 2018; Lei et al., 2019). In the context of small and medium enterprises (SMEs), prior studies indicated that because SMEs are limited resources, their innovation capability becomes very important to compete successfully in the marketplace (Sengphet et al., 2019). However, it is not easy for SMEs to develop it properly due to lack of understanding on antecedents of innovation (Le \& Lei, 2019; Sengphet et al., 2019). To fill the theoretical gaps, this study will clarify the influence of transformational leadership (TL) on innovation capability of SMEs via the mediating role of knowledge sharing. This study is expected to significantly expand the theory and bring valuable insight of innovation management by following reasons.
\end{abstract}


First, leaders play a decisive role in the failure or success of an organization (Le et al., 2018; Le \& Lei, 2019). Each leadership style has a certain significance and influence on aspects of innovation capability (Lei et al., 2020). Moreover, among leadership styles, TL is widely consented as one of the most dominant leadership styles facilitated innovation capabilities for firms (Le \& Lei, 2019; Islam et al., 2018). TL has become the hot issue that appealed the much interest of researchers and practitioners for examining leadership-innovation relationship (Hu et al., 2013; Le \& Lei, 2019; Phong \& Son, 2020). However, according to Le and Lei (2019), "knowledge of the direct correlation between TL and innovation capability remains underdeveloped and insufficient. It still exists the theoretical and empirical gaps in TL-innovation relationship that need to continue exploring and studying." So the first goal of this study is to explore the TL-innovation relationship by proposing the first research question.

RQ1. Does TL positively predict innovation capability?

Second, although knowledge sharing is considered as a key driver of fostering innovation capability of organization (Le \& Lei, 2019; Nguyen et al., 2021; Than et al., 2021), the full understanding on the correlation among these factors is still limited that is suggested to continuously explore, especially in case of examining the effects of KS on specific aspects of innovation such as individual and organizational innovation capability (Le \& Lei, 2019; Lei et al., 2020). As a result, investigating the correlation between knowledge sharing and two specific aspects of innovation namely individual and organizational innovation capability will significantly address this issue. Consequently, this study proposes the second research question:

$R Q 2$. Does knowledge sharing significantly contribute to individual and organizational innovation capability?

Third, prior studies have suggested the positive effects of TL on knowledge sharing (Le \& Lei, 2017; Le et al., 2018) which in turn significantly related to innovation capability (Yang et al., 2018). However, according to the author's knowledge, lack of study has examined the mediating role of knowledge sharing activities between TL and two specific forms of innovation capability namely individual and organizational innovation capability. This has limited our understanding on the mediating processes or specific solutions according to which transformation leaders can follow to foster innovation capabilities for firms. Accordingly, third research question arises as follows.

$R Q 3$. Does $K S$ mediate the relationship between TL and innovation capabilities?

To clarify three research questions above, this paper has reviewed the literature and used the data gathered from the survey questionnaires in the contexts of Lao SMEs. We expect to offer specific and useful guidance for Lao firms to succeed in following and improving their innovation capabilities.

\section{Literature Review and Hypothesis}

\section{The Effect of Transformational Leadership on Innovation Capability}

Innovation capability is one of the most important dynamics that enable firms to attain competitive advantage and success in long term in comparison with the key rivals (Le \& Lei, 2018; Le \& Lei, 2019; Phong \& Tung, 2021). Lei et al. (2020) defined innovation as the capabilities of development and implementation of new ideas or behavior relating to a system, policy, program, device, process, product or service by people who engage in transactions over time with others within an organization. Although innovation capability of firm can be classified into various categories (Le \& Lei, 2019), this study focuses on investigating the innovation capability at two facets namely individual and organizational innovation capability. Individual innovation capability refers capability of employees in generating and realizing new ideas. It reflects the activities of each employee for improving innovation at the individual level (Lei et al., 2020). Meanwhile, organizational innovation capability refers organizational capabilities of developing and implementing new ideas at the organizational 
level. In other words, organizational innovation capability reflects the innovation situation in general resulting from the innovation activities of all employees and all activities of organization (Lei et al., 2020). According to Lei et al. (2020), this classification is very useful and important because they are two different levels of innovation for reflecting a fully strategic orientation for organizational innovation.

TL is well known as one of the super leadership styles that notably associated with organizational capabilities for innovation (Le \& Lei, 2019; Lei et al., 2020; Le \& Tran, 2020). Scholars describes the transformational leaders with four attributes namely idealized influence, intellectual stimulation, inspirational motivation, and individualized consideration (Bass, 1990; Phong \& Son 2020). Le and Lei (2017) stated that "TL characterizes leaders who emphasize clarity in their communications about organizational goals, acting as the organization's leading force, engaging in active coaching, promoting new skill development among their followers and continuously seeking new opportunities for organizational development". Many prior studies indicated that TL has significant influences on the firm's innovation capability. Indeed, according to Phong et al. (2018), transformational leaders encourage employees freely in discussing and trying out innovative ideas and approaches through which positively affect firm's innovation capability (Phong et al., 2018). Transformational leaders directly or indirectly influence innovation capability of firms through improving learning capability of a firm (Van et al., 2018; Khan, et al., 2019). Especially, regarding the relationship between TL and individual innovation capability, Moriano et al. (2014) showed that TL is positively associated with innovativeness and risk taking which are key antecedents of innovation capability of individuals. Schuckert et al. (2018) argued that the TL is significantly associated with individuals' behavior of creativity and innovation. Regarding the relationship between TL and innovation capability of organization, Li et al. (2018) reported that, transformational leaders act as key antecedents to create and foster a positive organizational culture for organizational innovation. Le and Lei (2019) indicated that transformational leaders are successful in building a positive climate for knowledge sharing among employees to directly and indirectly enhance innovation capability of organizations. In particular note, empirical research of Lei et al. (2020) revealed that TL is significantly related to both individual amd organizational innovation capability. So following hypotheses are tested (Figure 1):

Hla.TL significantly predicts individual innovation capability.

HIb. TL significantly predicts organizational innovation capability.

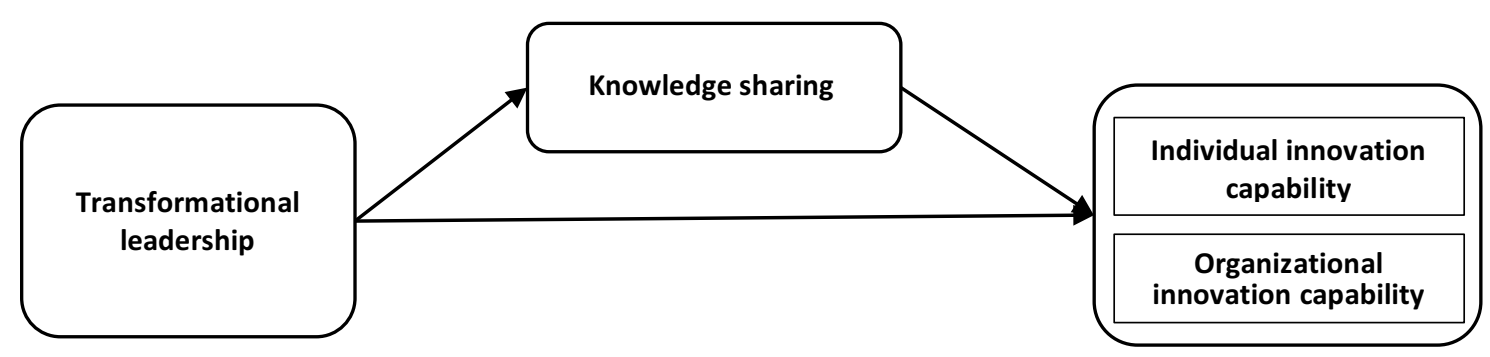

Figure 1. Proposed research model

\section{The Mediating Role of Knowledge Sharing}

Knowledge sharing are considered a key element in the process of managing knowledge of organizations (Le \& Lei, 2018; Lei et al., 2019). Le and Lei (2019) defined knowledge sharing "as the process of interchanging knowledge and experience among individuals that helps individuals to equip and complement new and valuable knowledge/skills for each other to achieve both personal and organizational goals". These scholars indicated that the successful extent of initiatives of knowledge management mainly depends on the effectiveness of knowledge sharing activities in an organization. So knowledge sharing activities have a great potential and benefits for firms to follow and enhance innovation capability. 
TL widely seen as a key factor for fostering knowledge sharing activities in organizations (Le \& Lei, 2017; Le \& Lei, 2018; Le, 2020; Son et al., 2020). For examples, Le and Lei (2017) indicated that TL practices allow CEOs and managers to build justice and the trust of their followers by which they can positively stimulate knowledge sharing behaviors among employees. Le and Lei (2018) stressed that transformational leaders play an important role in promoting the willingness of employees toward knowledge sharing behaviors in two ways: "willing to share knowledge in an active way without conditions" and "proactive in collecting or seeking knowledge". Recently, Lei et al. (2019) and Lei et al. (2021) supposed that TL is interested in setting up knowledge supportive culture through developing a set of values, assumptions, and beliefs to shape followers' behaviors toward performing knowledge activities and engaging in knowledge management process. Their empirical findings showed positive effects of TL on knowledge sharing activities of employees. These arguments support following hypothesis:

H2.TL is significantly associated with knowledge sharing activities of employees.

The positive effects of knowledge sharing toward innovation capability were shown by many prior researches (Wang \& Wang, 2012; Zheng et al., 2017; Le \& Lei, 2018). According to Le and Lei (2018), knowledge and learning capability is positively associated with organizational capability for innovation speed and innovation quality. Jantunen (2005) found that knowledge sharing activities among employees can create superior innovation capability for firms. Wang and Wang (2012) indicated that KS process contributes to innovations in teams, units and the entire organization because innovation initiatives mainly depend on knowledge and skill of employees in the process of creating value and their capability to transform and apply knowledge in producing goods and services. The findings of Zheng et al. (2017) showed the evidence that KS activities are positive associated with firm's innovation capability. Based on the above arguments, to provide clearer understanding on the relationship between knowledge sharing on two aspects of innovation performance, this study hypothesizes that:

H3a. Knowledge sharing significantly predicts individual innovation capability.

H3b. Knowledge sharing significantly predicts organizational innovation capability.

Above discussion provides significant supports for the mediating role of knowledge sharing activities between TL's and innovation capability. Thus, this study argued that by creating appropriate environment for stimulating knowledge sharing activities of employees, transformational leaders can make their followers become more creative and innovative. This is an important basis for firms to increase innovation capability in terms of individual and organizational innovation capabilities. So, following hypotheses are proposed:

H4a. KS activities mediate TL's effect on individual innovation capabilities.

$H 4 b$. KS activities mediate TL's effect on organizational innovation capabilities.

\section{Sample and Procedure}

\section{Methodology}

This study used convenient sampling method to collect data from 45 small and medium firms in Vientiane, Laos during the period from July to November, 2020. We communicated with representatives of these firms who mainly worked in human resources departments by phone and/or make personal visits to explain the purpose of the research, committing to information security for respondents, and ask for their assistance in collecting. The respondents in this study need to be key employees who are directors/managers, head of departments, team leaders, and employees at departments of administration to ensure having full understanding on firm's business situation. Questionnaires were sent directly to these representatives by personal visits between June and August 2018. This study issues 350 questionnaires and receives 281 ones in the formal data collection, among which 216 ones are valid, with a $61.7 \%$ valid rate. 


\section{Measurement}

To ensure the validity and reliability of the study, items used to measure variables were developed from previous studies. All constructs were measured using multiple items and all items were evaluated using a five-point Likert-type scale, ranging from " 1 = strongly disagree" to " $5=$ strongly agree."

Transformational leadership. This study uses eight items adapted from the study of Son et al. (2020) to measure TL style of leaders. A sample item is, "My supervisor always acts as the organization's leading force." Knowledge sharing is measured by using 10 items adapted from the research of Yang et al. (2018). A sample item is "I am usually willing to share my knowledge and experience with others". Finally, this study used 15 items derived from the works of Janssen (2000) and Akman and Yilmaz (2008) to measure two aspects of innovation. Individual innovation capability is measured by nine items, a sample item is "We alway search out new working methods, techniques, or instruments"; and organizational innovation capabilities is measured by six items, a sample item is "Our firm has an organisational culture and a management comprehension that support and encourage innovation."

\section{Data analysis methods}

The Structural Equation Modeling (SEM) method has been widely use due to its ability to demonstrate versatile regression correlations on a single model and test (Kline, 2015). So this study used SEM to test proposal hypotheses in the research model. In addition, a bootstrapping procedure was also used for the significance tests of the key research hypotheses. Statistical Package for the Social Sciences (SPSS 22) and Analysis of Moment Structures (AMOS 22) are employed for assessing the data gathered from the 216 respondents in 45 manufacturing and service SMEs.

\section{Measurement Model}

\section{Analysis of Empirical Results}

As shown in Table 1, a series of tests are performed to assess the validity and reliability of the constructs.

Table 1. Descriptive statistics and average variances extracted from constructs

\begin{tabular}{|c|c|c|c|c|c|c|c|c|c|}
\hline Construct & AVE & $\mathrm{CR}$ & $\mathrm{C} \alpha$ & Mean & SD & TL & KS & IIC & $\mathrm{OIC}$ \\
\hline Transformational leadership (TL) & 0.73 & 0.96 & 0.95 & 3,33 & 0.54 & 0.85 & & & \\
\hline Knowledge sharing (KS) & 0.68 & 0.95 & 0.96 & 3.41 & 0.63 & 0.56 & 0.82 & & \\
\hline Individual innovation capability (IIC) & 0.78 & 0.97 & 0.97 & 3.70 & 0.62 & 0.70 & 0.62 & 0.88 & \\
\hline Innovation performance (OIC) & 0.83 & 0.97 & 0.96 & 3.72 & 0.69 & 0.70 & 0.61 & 0.80 & 0.91 \\
\hline
\end{tabular}

Note: $C \alpha \geq 0.7 ; C R \geq 0.7 ; A V E \geq 0.5$; Diagonal elements (in bold) are the square root of the AVE.

Specifically, to assess the reliability of the latent variables, basing on suggestion of Nunnally and Bernstein (1994), this study used the Cronbach's alpha coefficients of each one that require greater than the level of 0.7. Confirmatory factor analysis (CFA) to test for the convergent validity; comparing the squared correlations between the latent variables and square root of average variance extracted (AVE) to test the discriminant validity of measures (Fornell \& Larcker, 1981).

Results in Table 1 showed AVE, CR, mean, standard deviation (SD) and C $\alpha$. These results have provided the evidence for the evidence on the reliability of scales as well as the convergent validity of constructs.

In addition, to evaluate the discriminant validity of latent constructs in the proposal model, the paper used the squared correlations among the latent factors to control whether they are smaller than each latent variable's square root of AVE or not. Table 1 also points out that the squared correlations among the latent factors are lower than square root of AVE of each one (diagonal elements in bold). Thus, according to Fornell and Larcker (1981), the results have provided significant support for the scales' discriminant validity.

Fit indices of the measurement model obtained from CFA model show that the model fits the data (see Table 2). 
Table 2. Overall fit index of the CFA model

\begin{tabular}{lll}
\hline Fit index & Scores & Recommended value \\
\hline Absolute fit measures & & \\
CMIN/df & 1.935 & $\leq 2 ; \leq 55^{\circ}$ \\
GFI & 0.800 & $\geq 0.90 ; \geq 0.80^{\circ}$ \\
RMSEA & 0.066 & $\leq 0.8 ; \leq 0.10^{\circ}$ \\
Incremental fit measures & & \\
NFI & 0.905 & $\geq 0.90 ;$ \\
TLI & 0.947 & $\geq 0.90 ;$ \\
CFI & 0.951 & $\geq 0.90 ;$ \\
\hline
\end{tabular}

Notes: a Acceptability: acceptable; b Acceptability: marginal

\section{Findings}

The paper applied Structural equation model with procedures of maximum likelihood estimation to examine the proposal hypotheses. The findings indicated that the fit indices of the proposal model are satisfactory $(\chi=1000.7 ; \mathrm{df}=481 ; \mathrm{RMSEA}=0.071 ; \mathrm{GFI}=0.800 ; \mathrm{CFI}=0.944 ; \mathrm{TLI}=0.938)$. The results have pointed out that the correlation among latent factors fit the data. The main findings of this study are shown in Table 3 and Figure 2.

\section{Direct Effect Analysis}

The results in Table 3, and Figure 2 verified that direct effects of independent factors on dependent factors are found to be significant supported hypotheses H1a.b, H2, and H3a.b.

Specifically, influences of TL on individual and organizational innovation capability are statistically significant, favoring for hypothesis H1a.b. The results showed that the impacts of TL on organizational innovation capability $(\beta=0.533 ; p<0.001)$ is more significant than its influences on individual innovation capability $(\beta=0.524 ; p<0.001)$.

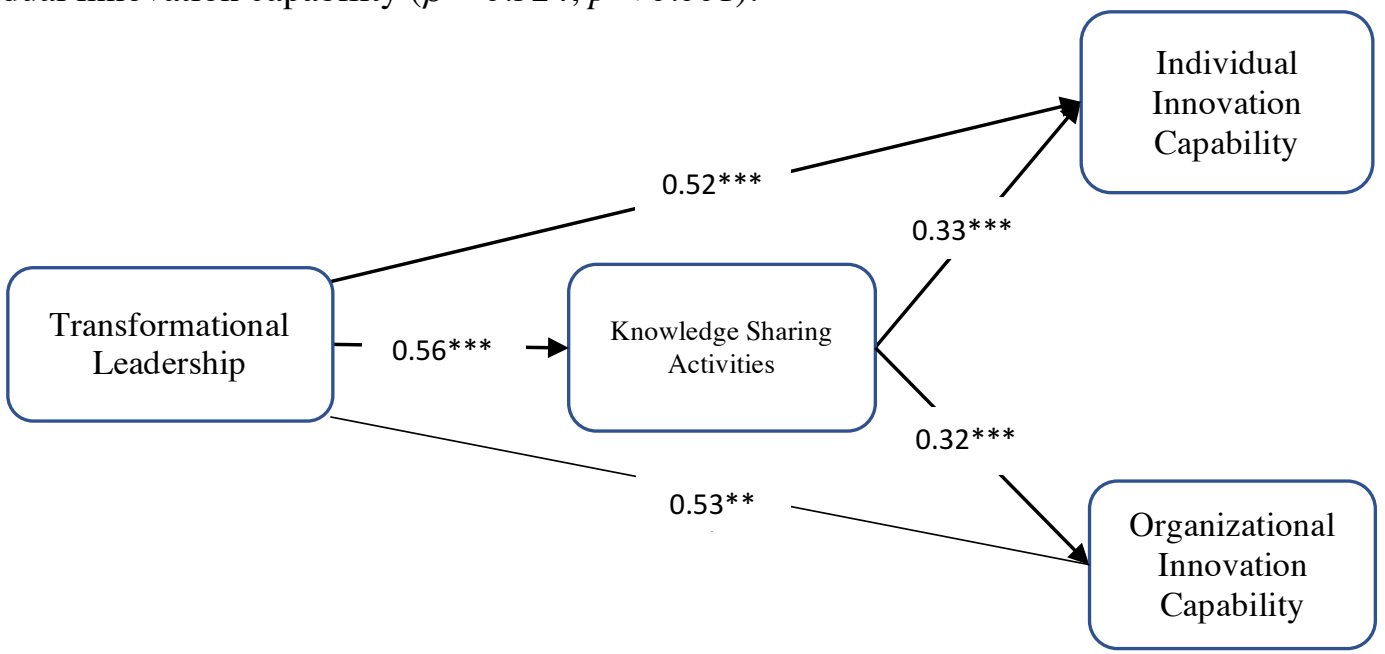

Figure 2. Path coefficients of the structural model

Note: $* * * P<0.001$

Hypothesis $\mathrm{H} 2$ relating to the influence of TL on KS activities are also statistically significant and quite large $(\beta=0.565 ; p<0.001)$, so hypothesis $\mathrm{H} 2$ is supported.

The findings in Table 3 also confirmed the positive effect of knowledge sharing activities on two aspects of innovation capability and revealed that influence of knowledge sharing on individual innovation capability $(\beta=0.330 ; p<0.001)$ is more significant than impact of its effect on organizational innovation capability $(\beta=0.320 ; p<0.001)$. 
Table 3. Structural model results

\begin{tabular}{|c|c|c|c|c|}
\hline Hypotheses & Effect & Estimate & $t$-value & Results \\
\hline H1a. Transformational leadership $\rightarrow$ Individual innovation capability & + & $0.524 * * *$ & 8.316 & Supported \\
\hline H1b. Transformational leadership $\rightarrow$ Organizational innovation capability & + & $0.533 * * *$ & 8.771 & Supported \\
\hline H2. Transformational leadership $\rightarrow$ Knowledge sharing & + & $0.565 * * *$ & 9.011 & Supported \\
\hline H3a. Knowledge sharing $\rightarrow$ Individual innovation capability & + & $0.330 * * *$ & 5.640 & Supported \\
\hline H3b. Knowledge sharing $\rightarrow$ Organizational innovation capability & + & $0.320 * * *$ & 5.587 & Supported \\
\hline
\end{tabular}

Notes: $* * * P<0.001 ; * * P<0.05$.

\section{Indirect Effect and Total Effect}

The paper does not just give evidence about the direct influence of TL on aspects of innovation capability. It also demonstrates how knowledge sharing activities mediate the relationship between TL and innovation capability.

According to the recommendation of Preacher and Hayes (2008), to show the evidence for the mediating role of knowledge sharing between TL behavior and innovation capability, the paper has applied procedure of bootstrap confidence intervals with 3,000 iterations to examine and assert the indirect effects' immensity and statistical significance. The results are shown in the Table 4.

Table 4. Test for indirect effects

\begin{tabular}{|c|c|c|c|c|c|}
\hline \multirow[b]{2}{*}{ Path } & \multirow{2}{*}{$\begin{array}{l}\text { Direct } \\
\text { effects }\end{array}$} & \multirow{2}{*}{$\begin{array}{l}\text { Indirect } \\
\text { effects }\end{array}$} & \multirow[b]{2}{*}{ Total effects } & \multicolumn{2}{|c|}{ Bias-corrected confidence intervals } \\
\hline & & & & $\begin{array}{l}\text { Lower } \\
\text { confidence level }\end{array}$ & $\begin{array}{l}\text { Upper } \\
\text { confidence level }\end{array}$ \\
\hline $\mathrm{TL} \rightarrow \mathrm{KS} \rightarrow \mathrm{IIC}$ & $0.524 * *$ & $0.186^{* * *}$ & $0.710 * * *$ & 0.135 & 0.255 \\
\hline $\mathrm{TL} \rightarrow \mathrm{KS} \rightarrow \mathrm{OIC}$ & $0.533 * * *$ & $0.181 * * *$ & $0.714^{* * * *}$ & 0.129 & 0.248 \\
\hline
\end{tabular}

Table 4 showed indirect effect of TL on individual innovation capability $(\beta=0.186 ; p<0.001)$ and organizational innovation capability $(\beta=0.181 ; p<0.001)$ are statistically significant and lies in the confidence interval. Consequently, hypothesis H4a.b is significantly supported. In other words, the result of testing in Table 4 has firstly confirmed that employees' knowledge sharing activities significantly mediate the effects of TL on two aspects of innovation capability.

\section{Discussions and Conclusions}

Improving innovation capability has been recognized as a crucial factor for firms to cope with the challenges of uncertainty, increasingly competition, and attaint competitive advantage in the context of the rapid changes of business environment, industrial revolution, pursuing globalization, digitalization and free trade agreements (Vargas, 2015; Le \& Lei, 2018; Ha et al., 2019). Thus, how to successfully improve innovation capability for firms is always a top concern of scholars and practitioners. By investigating and highlighting the roles of TL and knowledge sharing activities as the important determinants of innovation capability, the paper has considerably contributed to advancing the development of theories of leadership, knowledge management and innovation management as following reasons.

First, recognizing the crucial role of leadership in facilitating innovation, scholars emphasized the need of examining the leadership-innovation relationship due to the links between leadership and the innovation capability have not been explicitly studied (Le \& Lei, 2019). By investigating the effects of TL on innovation capabilities of individuals and organization, the paper significantly contributes to filling the theoretical gaps, and highlights that TL is one of the most effective leadership styles significantly predicted both individual and organizational innovation capabilities. Specifically, the empirical findings reveal that the influences of TL on organizational innovation capability is greater than its effect on individual innovation capability. The findings imply that CEOs and managers of Lao firms should pay much attention to practicing TL style for strongly stimulating organizational capability for innovation. 
Second, an important contribution of this study is that providing deeper insight on the relationship between knowledge sharing activities of employees and two components of innovation capability. The empirical findings have verified the correlation among latent variables in the proposal model and confirmed the key role of knowledge sharing in stimulating both individual and organizational innovation capabilities. Specifically, the findings disclosure that knowledge sharing has a greater impact on individual innovation capability compared to its effects on organizational innovation capability. Generally, the findings on relationships between these constructs have brought many specific and useful guides for firms to enhance each aspects of innovation capability. In other words, to pursuit individual innovation capability, firms should focus on fostering the willingness of employees toward knowledge sharing activities. In contrast, to pursuit organizational innovation capability, firms should focus on applying TL style for their directors and managers.

Finally, although firm innovation capability is widely prescribed as a driving force of enhancing organizational performance and competitive advantage (Le \& Lei, 2018; Nguyen et al., 2019), scholars realized that organizations have to face with many challenges to successfully innovate (Le \& Lei, 2019; Lei et al., 2021). This leads to great attention among researchers to look for what enables firms to innovate (Le et al., 2020). Accordingly, by assessing the effects of TL on aspects of innovation capability via the mediating role of knowledge sharing activities, the findings of this study showed the evidence that TL practice might help firms to foster innovation capabilities of firms directly or indirectly through its effect on knowledge sharing. Consequently, to create the appropriate environment for KS and innovation, leaders of SMEs in Laos need to pay great attention on TL style practice.

\section{Research Limitation and Directions for Future Study}

Beside significant contributions, the paper still has some certain limitations. First, the paper use cross-sectional design, thus it might expose the cases that causal correlations might alter in the longrun. Therefore, longitudinal studies are necessary to surpass this restriction and confirm the findings of this study. Second, the paper has not investigated the impacts of control variables like industry type and firm size in the connection among the latent factors. Future works should inspect and examine deeper the correlation among them in case of testing these variables to bring more valuable understanding for scholars and practitioners. Third, the paper is only performed in the circumstances of medium and small firms, so the future work should examine the relationship among the latent factors in the broader circumstances to provide more meaning for firms. Finally, Gui et al. (2020) indicated that knowledge donating and knowledge collecting are two distinct and major aspects of knowledge sharing behavior of employees. This study only investigates the correlation among the latent factors in the research model in the relationship with knowledge sharing activities in general. Accordingly, future research should clarify the mediating role of knowledge collecting and knowledge donating between TL and specific aspects of innovation capability to bring deeper insight on these relationships.

Overall, the paper has shown the empirical evidence to spotlight that TL style and employees' KS activities significantly contribute to foster individual and organizational innovation capability. The paper has significantly advanced the innovation management theory by offering an integrative model and a specific pathway for pursuing two different types of innovation capability. The paper implies that by focusing on practicing TL style, directors and managers can successfully stimulate KS activities of employees for improving organizational capabilities for innovation.

\section{References}

Akman, G., \& Yilmaz, C. (2008). Innovative capability, innovation strategy and market orientation: an empirical analysis in Turkish software industry. International journal of innovation management, 12(01), 69-111.

Bass, B. M. (1990). From transactional to transformational leadership: Learning to share the vision. Organizational dynamics, 18(3), 19-31. 
Fornell, C., \& Larcker, D. F. (1981). Evaluating structural equation models with unobservable variables and measurement error. Journal of marketing research, 18(1), 39-50.

Gui, L., Lei, H., \& Le, P. B. (2021). Determinants of radical and incremental innovation: the influence of transformational leadership, knowledge sharing and knowledge-centered culture. European Journal of Innovation Management. DOI: https://doi.org/10.1108/EJIM12-2020-0478.

Hu, H., Gu, Q., \& Chen, J. (2013). How and when does transformational leadership affect organizational creativity and innovation? Critical review and future directions. Nankai Business Review International, 4(2), 147-166.

Islam, M. A., Jantan, A. H., Rahman, M. A., Hamid, A. B. A., Mahmud, F. B., \& Hoque, A. (2018). Leadership Styles for Employee Empowerment: Malaysian Retail Industry. Journal of Management Research, 10(4), 27-40

Janssen, O. (2000). Job demands, perceptions of effort-reward fairness and innovative work behaviour. Journal of Occupational and organizational psychology, 73(3), 287-302.

Jantunen, A. (2005). Knowledge-processing capabilities and innovative performance: an empirical study. European Journal of Innovation Management, 8(3), 336-349.

Khan, A. M., Jantan, A. H. B., Salleh, L. B. M., Datoâ, Z., Islam, M. A., \& Hosen, S. (2019). The impact of transformational leadership effects on innovative work behavior by the moderating role of psychological empowerment. Journal of Reviews on Global Economics, 8, 925-938.

Kline, R. B. (2015). Principles and practice of structural equation modeling. New York: The Guilford Press, Guilford publications, Inc.

Le, B. P., Lei, H., Phouvong, S., Than, T. S., Nguyen, T. M. A., \& Gong, J. (2018). Self-efficacy and optimism mediate the relationship between transformational leadership and knowledge sharing. Social Behavior and Personality: an international journal, 46(11), 1833-1846.

Le, B. P., \& Tran, Q. T. (2020). Leadership Practice for Building Trust of Followers: Decisive Factors of Organizational Performance. SEISENSE Journal of Management, 3(2), 45-57.

Le, P. B. (2020). How transformational leadership facilitates radical and incremental innovation: the mediating role of individual psychological capital. Asia-Pacific Journal of Business Administration, 12(3/4), 205-222.

Le, P. B., \& Lei, H. (2017). How transformational leadership supports knowledge sharing: Evidence from Chinese manufacturing and service firms. Chinese Management Studies, 11(3), 479497.

Le, P. B., \& Lei, H. (2018). The effects of innovation speed and quality on differentiation and lowcost competitive advantage: The case of Chinese firms. Chinese Management Studies, 12(2), 305-322.

Le, P. B., \& Lei, H. (2019). Determinants of innovation capability: the roles of transformational leadership, knowledge sharing and perceived organizational support. Journal of Knowledge Management, 23(3), 527-547.

Le, P. B., Lei, H., Le, T. T., Gong, J., \& Ha, A. T. (2020). Developing a collaborative culture for radical and incremental innovation: the mediating roles of tacit and explicit knowledge sharing. Chinese Management Studies, 14(4), 957-975.

Lei, H., Gui, L., \& Le, P. B. (2021). Linking transformational leadership and frugal innovation: the mediating role of tacit and explicit knowledge sharing. ournal of Knowledge Management (In press), 25(7), 1832-1852.

Lei, H., Leaungkhamma, L., \& Le, P. B. (2020). How transformational leadership facilitates innovation capability: the mediating role of employees' psychological capital. Leadership \& Organization Development Journal, 41(4), 481-499.

Lei, H., Phouvong, S., \& Le, P. B. (2019). How to foster innovative culture and capable champions for chinese firms: an empirical research. Chinese Management Studies, 13(1), 51-69.

Li, W., Bhutto, T. A., Nasiri, A. R., Shaikh, H. A., \& Samo, F. A. (2018). Organizational innovation: the role of leadership and organizational culture. International Journal of Public Leadership, 14(1), 33-47. 
Moriano, J. A., Molero, F., Topa, G., \& Mangin, J.-P. L. (2014). The influence of transformational leadership and organizational identification on intrapreneurship. International Entrepreneurship and Management Journal, 10(1), 103-119.

Nguyen, T. N., Shen, C. H., \& Le, P. B. (2021). Influence of transformational leadership and knowledge management on radical and incremental innovation: the moderating role of collaborative culture. Kybernetes, https://doi.org/10.1108/K-12-2020-0905.

Nunnally, J. C., \& Bernstein, I. (1994). Elements of statistical description and estimation. Psychometric Theory 3 Edition, McGraw-Hill, New York.

Phong, L. B., Hui, L., \& Son, T. T. (2018). The mediating role of knowledge sharing in linking transformational leadership and innovation. The 5th IBSM International Conference on Business, Management and Accounting, Hanoi University of Industry, Vietnam. 791-799.

Phong, L. B., \& Son, T. T. (2020). The Link Between Transformational Leadership and Knowledge Sharing: Mediating Role of Distributive, Procedural and Interactional Justice. Journal of Information Knowledge Management, 19(3), 2050020.

Preacher, K. J., \& Hayes, A. F. (2008). Asymptotic and resampling strategies for assessing and comparing indirect effects in multiple mediator models. Behavior research methods, 40(3), 879-891.

Schuckert, M., Kim, T. T., Paek, S., \& Lee, G. (2018). Motivate to innovate: How authentic and transformational leaders influence employees' psychological capital and service innovation behavior. International Journal of Contemporary Hospitality Management, 30(2), 776-796.

Sengphet, P., Hui, L., \& Phong, L. (2019). The Pathway to Improve Innovation Capacity for Lao Firms: The Roles of Transformational Leadership and Psychological Resources of Employees. Journal of Business Administrative Studies, 5(2), 224-239.

Son, T. T., Phong, L. B., \& Loan, B. T. T. (2020). Transformational Leadership and Knowledge Sharing: Determinants of Firm's Operational and Financial Performance. Sage Open, 10(2), 2158244020927426.

Than, S. T., Le, P. B., \& Le, T. T. (2021). The impacts of high-commitment HRM practices on exploitative and exploratory innovation: the mediating role of knowledge sharing. VINE Journal of Information Knowledge Management Systems, DOI: https://doi.org/10.1108/VJIKMS-10-2020-0196.

Van, N. T., Phong, L. B., \& Loan, L. T. (2018). Antecedents of Innovation Capability: The Role of Transformational Leadership and Organizational Learning. International Journal of Business Administration, 9(5), 1-10.

Vargas, M. I. R. (2015). Determinant factors for small business to achieve innovation, high performance and competitiveness: organizational learning and leadership style. ProcediaSocial and Behavioral Sciences, 169, 43-52.

Wang, Z., \& Wang, N. (2012). Knowledge sharing, innovation and firm performance. Expert systems with applications, 39(10), 8899-8908.

Yang, Z., Nguyen, V. T., \& Le, P. B. (2018). Knowledge sharing serves as a mediator between collaborative culture and innovation capability: an empirical research. Journal of Business \& Industrial Marketing, 33(7), 958-969.

Zheng, J., Wu, G., \& Xie, H. (2017). Impacts of leadership on project-based organizational innovation performance: The mediator of knowledge sharing and moderator of social capital. Sustainability, 9(10). 